\title{
Demand for Education in Kenya: The Effect of School Uniform Cost on Access to Secondary Education
}

\author{
Reuben Gitonga Mutegi (PhD) \\ School of Education, University of Nairobi, Nairobi, Kenya
}

Doi: 10.19044/ejes.v5no2a3

URL:http://dx.doi.org/10.19044/ejes.v5no2a3

\begin{abstract}
This paper examines the actual cost of school uniform by age, gender, class and type of school and how it influences pupils' access to secondary education in Kenya. The study used correlational research design and targeted all the 26 secondary school principals and 23,275 household heads in Tharaka south Sub-county, Kenya. The sample size constituted all the 26 school principals and 393 household heads sampled using Yamane (1967) formulae. The data was collected from school principals using questionnaires and from household heads using interview guide. The data was analysed using descriptive statistics such as percentages, means and standard deviation as inferential statistics like correlation and t-test. Through data analysis, the study established that the cost of uniform for girls is $12 \%$ higher than that of boys. It also found that students in boarding schools spend more on school uniform compared to those in day schools at Ksh 4,779 and Ksh 4,143 respectively. The study also revealed a variation on cost of uniform in relation to class level where on average, a student in Form 1 spends Ksh 5,375 on uniform compared to those in Form 2 who spends Ksh 4,706, Form three Ksh 3,917 and Form four 4,325 respectively. Finally, the study established that, there is a relationship between the cost of school uniform and access to secondary education $(r=0.834, N=333, p<0.0010)$ implying that the cost of school uniform determines pupils chances to access secondary education in Kenya. The results lead to a recommendation that the government of Kenya in partnership with other educational stakeholders should subsidise the cost of school uniforms for the government achieve 100\% transition rate from primary to secondary educations as envisioned in the policy of Free Day Secondary Education.
\end{abstract}

Keywords: Access, Uniform cost and Effect. 


\section{Introduction}

The policy of school uniform has been of interest to scholars for a long time. This is as evidenced by many scholars who have attempted to explain the role of school uniform in relation to students' performance, access to school and unifying factor in schools. For instance, Anderson (2002) asserted that in the United States the phrase "Dress right, act right" was heard often in schools in the 1950s and 1960s during campaigns to curb "juvenile delinquency." Anderson, (2002) further alluded that in the 1950s, many school dress codes forbade girls from wearing slacks. According to Anderson, (2002) in the 1960s, many school administrators in the USA outlined the specifications of school uniform and banned several types of uniform. For instance, short skirts for girls were banned, blue jeans, motorcycle boots, and black leather jackets were also banned for boys because they were considered dangerous attire and linked to gangs.

According to Brunsma (2004), in the 1980s uniform policies progressively grew to become an area of concern for education policy makers under the Reagan administration after a disturbing shooting at a Baltimore public high school. The first public school to heavily publicize its uniform policy with the aim of increasing access to schools was Cherry Hill Elementary School in Baltimore, Maryland, in the fall of 1987 (Brunsma, 2004). The initial policy was put into practice based on the original idea that uniforms would relieve economic pressures on parents by reducing clothing costs and reducing the social pressures their children would face on a daily basis in school (Brunsma, 2004).

According to Mathison and Ross (2008), the first documented discussion regarding school uniforms as an option for public schools came from the Barry administration, when the Washington DC mayor Marion Barry began the discussion for a mandatory uniform policy. Barry proposed that a school-wide policy would foster school spirit and deter infiltration from unwanted outsiders. By 1989, five Baltimore Public schools had enacted a uniform policy. "In 1996, at the direction of President Clinton, the U.S. Department of Education published and disseminated a Manual of School Uniforms to all 16,000 schools in 1994; Long Beach, California became the first large urban school district in the United States to require all students from kindergarten through eighth grade to wear uniforms.

Despites the emphasis on the use of uniform in schools, scholars have cited school uniform as one of the direct cost associated with education (Schultz, 1993 \& Basu, 1999). For instance, Schultz, (1993), asserted that the cost of uniform influences school enrolment. In his work, Bonke (2013) established that cost of school uniform influences access to school and he therefore recommended the need to lower the costs or subsidize schooling programmes in order to make education affordable. According to Bonke 
(2013), in developing countries ancillary costs of education like school uniforms continue to impede education access. As a true reflection of Bonke (2013) observations, In Kenya, a program that provided free uniforms to students increased their attendance by 6.4 percentage points, buying 0.71 additional years of education per $\$ 100$. Another Kenyan study showed that providing scholarships to cover school fees significantly increased attendance, causing 0.27 additional years of education per $\$ 100$ spent (Bonke (2013),

In a bid to relieve parents from the burden of paying school fees in line with EFA and MDG, the government of Kenya introduced a policy of Free Day Secondary Education (FDSE). This policy aimed at increasing access to secondary education as indicated in the Republic of Kenya, (2002b); MoEST, (2004, 2005) Sessional Paper No.1 of 2005 by then Ministry of Education Science and Technology (MoEST). These documents underscored that the costs of secondary education were the main reason for low transition rate to secondary education. With the introduction of FSE policy, the cost of secondary education was expected to go down. However, despite the government intervention of making secondary education free in order to increase access to secondary education, the cost of education remained high because households are supposed to provide non-discretionary items such as school uniforms, sports uniforms, books, and stationery (Ohba, 2009). This study, therefore, sought to establish the cost of school uniform incurred by household in relation to age, gender, level of education, and type of school attended by learners and the extent to which cost of uniform influence access to secondary education.

\section{Statement of the problem}

The Kenyan government main intention is that all children access secondary education without discrimination in accordance with the United Nation's charter of 1947 where every child has a right to education. The United Nation's charter of 1947 prompted the government of Kenya to introduce Free Day Secondary Education (FDSE). The policy requires the households to meet other non-discretionary cost of education such as school uniform. However, after the introduction of FDSE in 2008, there is no evidence of a study conducted to establish the cost of education in relation to school uniform. This study therefore aimed at establishing the uniform cost differentials by age, gender, level of education, and type of school attended by learners and the extent to which cost of uniform influence access to secondary education in Kenya. 


\section{Objectives of the Study}

The study was guided by the following objectives

i. To determine uniform cost differentials by age and gender of the student in Kenya

ii. To establish uniform cost differentials by students level of education and category of school in Kenya

iii. To establish the influence of cost of school uniform on access to secondary education in Kenya.

\section{Literature review}

The provision of subsidized secondary education is an attempt to fulfil the Jomtien Declaration of 1990 (EFA) in which citizens are given an opportunity to explore their abilities to ensure equitable distribution of development. The initiatives saw two conferences being held in 1990, the Jomtien, Thailand followed by another in 2000 in Dakar Senegal. The two conferences advocated for suitable access to education as a development strategy and considered a literate population as key to overall development to any nation. The declarations gave the impetus to education in many countries to ensure that learning of all young adults was met through equitable access to appropriate learning and life skills programme (MoEST, 2003).

In Kenya, under the subsidized secondary education, the government takes care of recurrent social cost (RSC) and capital/development social cost (CSC), which are both added together to give the total social cost (TSC) of education, that is TSC $=\mathrm{RSC}+\mathrm{CSC}$. It takes care of teachers' salary, tuition fee, examination fee, school development (physical facilities) and bursaries among other costs. Apart from the government, households are expected to meet the cost of uniform, supplementary books, meals, boarding fees, motivation fee and transport. In this case, the decision on who pays what is clearly defined and the responsibility of providing school uniform rests on households. This paper therefore sought to establish the amount spent on every students and the extent to which school uniform influences access to secondary education in Kenya.

Generally, several studies have been carried out to investigate the various aspect of school uniform. For instance, Draa (2005) conducted a quasiexperimental study in Ohio to determine the impact of implemented mandatory school uniform policies on academic achievement. The results indicated that there is a significant positive effects of school uniform on attendance, with little significant effects on graduation rates, and incoherent effects on reading and mathematics achievement.

In relation to the adoption of school uniform policy, Daugherty (2001), established that about $60 \%$ of schools that adopt uniform policies make them mandatory and the other $40 \%$ opt for the voluntary wearing of uniforms. 
Daugherty (2001) further established that majority of the student body and about $70 \%$ of the faculty and staff wore the mandatory uniforms, however, as the school year came to an end, the involvement by the student body had dropped from majority to about $50 \%$. Although the implementation of the voluntary uniform policy program only achieved some of its initially set goals of improving school safety, enhancing academics, and attendance, the school principal recommended that the school board adopt a policy of mandatory uniforms.

Other studies have examined the effect of reducing the cost of schooling by providing uniforms. For instance, Kremer et al. (2002b) examined the impact of uniforms among a bundle of goods provided to schools while Duflo et al. (2006) examined the impact of providing uniforms to older primary school students on dropout rates, teen marriage and childbearing. The two studies indicated that reducing the cost of schooling by providing uniforms among other inputs increases school participation.

\section{Methodology}

This study embraced correlational research design. According to Orodho (2003) correlational design analyses the relationship between variables with the aim of establishing the relationship between the dependent and independent variables. In this case, this study sought to establish the relationship between the cost of uniform and access to secondary

The target population included all 23,275 household heads and 26 secondary school heads in Tharaka south sub county. The school principals were sampled using census techniques because the number of schools were few while the household heads were sampled using Yamane (1967) formulae as follows.

$$
\mathrm{n}=\frac{\mathrm{N}}{1+\left(\mathrm{Ne}^{2}\right)} \quad \begin{array}{r}
\text { Where } ; \mathrm{n}=\text { minimum desired sample size } \\
\mathrm{N}=\text { the target population }(23275) \\
\mathrm{e}=\text { degree of precision }(5 \%)
\end{array}
$$

Therefore, by substitution:$$
\mathrm{n}=\left[\frac{23275}{1+\left(23275 * 0.05^{2}\right)}\right]=393 \text { household heads. }
$$

Yamane (1967) formulae gave a sample size of 393 household heads. To select the specific households to participate in the study, a list of households was made with the help of the area chief (Government Administrator at Ward level). The names of household heads were written in a piece of paper and then folded. This was to give all the household heads an equal chance to participate in the study. The folded papers were then picked 
randomly using the pick-and- replacement method. That is, picking a paper, opening it and writing the name of the household down. The pater was folded and taken back again, after juggling another paper was picked. This ensured that the probability of picking a given household head remained equal throughout the exercise. For the school principals, the census technique was used where all the 26 public secondary school principals participated in the study.

\section{Results}

The demographic characteristics such as age, gender, class level and type of school were sought. The demographic data was of interest in order to establish whether transport cost differs by the characteristic of the student. The age distribution of the statements was as presented in Figure 1. (See appendix pp10)

Figure 1 indicates that the peak of the age of the students in the secondary is 16 years. This is an indication that, for both boys and girls, most of them are of age 16 years. The age distribution by gender mimics each other up to age 16 where they both sharply drop. However, for the boys, they drop up to age 18 and slightly rises up to age 19 and then drop again. For the case of girls, the number drops all through from age 16 up to age 21 . This result points out that, there are more elderly girls in secondary schools compared to boys. This can be attributed to household chores and other cultural practices such as FGM and early pregnancies which mostly affects girls schooling compared to the boys.

On gender, the results are as shown in Figure 2. Which shows that at formative classes, that is form 1 and 2 , the number of girls supersedes that of the boys. For instance, in form one; girls are more than boys at 53\% and 47\% respectively. In form 2 , the number of girls is more than the number of boys at $68 \%$ and $32 \%$ respectively. However, at form three and four, the trend reverses and the number of boys surpasses the number of girls. In form three boys are more than the girls at $56 \%$ to $44 \%$ and in form four $53 \%$ and $47 \%$. This is an indication that the dropout rate for girls is more than the drop out for the boys and the enrolment for girls is more than the enrolment for boys in lower classes.

The results in Figure 3 indicates that, most of the schools in Tharaka Sub-county are day schools as attested by $54 \%$ of school principals. The rest of the principals $31 \%$ and $15 \%$ indicated that they head Boarding schools as well as Day and Boarding school respectively. This implies that most of secondary schools in Tharaka South sub-county are day schools mostly established through Constituency Development Fund kitty.

On the actual uniform cost by gender, the results are as presented in Table 1 which indicates that girls' uniform is costlier than the boys' uniform. 
For girls on average, a girl spends Ksh 5,094.73 and boys spend Ksh 4,035.75 on school uniform every year. This constitutes an average of $12 \%$ higher costs for the girls compared to the boys or Ksh 1059 per year. This shows that parents with girls in secondary schools spend more on school uniform for their children hence upscaling their unit cost.

Figure 4 shows that parents with children of age 13 spend less money on school uniform compared to parents with children in other age groups. However, at age 14-18, parents spend almost the same amount on school uniform. After age 18, school uniform cost sharply goes down up to age 19 and then increases to Ksh 6,500 at the age of 23 years. In Kenya, secondary school age going ranges from age 14-18 where school uniform seems to be the same ranging from Ksh 4,831 to Ksh 4,872.

In line with school category, the study established that students in boarding schools spend more money on uniform than those in day school. In day schools, the average expenditure on school uniform is Ksh 4,143 compared to Ksh 4,779 for those in boarding schools. This implies that children in boarding schools pay $8 \%$ higher on school uniform compared to the children in day schools.

When disaggregated by class as shown in Table 2, the study established that parents who have children in form one pay more on school uniform compared to those in other classes. On average a student in form 1 spends Ksh 5,375 on school uniform compared to parents in Form two who spend Ksh 4,706 Form 3 Ksh 3,917 and Form four Ksh 4,325. The form one uniform cost is up-scaled by the cost of school games uniform and the aspect of buying more pairs of uniform.

Correlational analysis was done to establish the relationship between age, gender and the cost of school uniform. The results are as presented in Table 3 which shows a positive strong correlation between the age of the students and cost of school uniform $(\mathrm{r}=858, \mathrm{~N}=401, \mathrm{p}<0.001)$. This suggests that, younger students spend less money to buy school uniform compared to children of high ages. This may be attributed to body size; children outgrowing their school uniform at advanced levels of education which increases the chances of replacing school uniform faster than at early ages. On gender, the results show that there is a very strong correlation between gender and school uniform ( $\mathrm{r}=824, \mathrm{~N}=401, \mathrm{P}<0.001)$. The results suggest that parents who have girls in secondary schools in Tharaka South Sub County spend more money on uniform compared to the parents with the boys in the same locality.

A t-test was carried out to establish whether the differences in means for the school uniform among different types of school by chance. The T-test results in Table 4 shows that school type has a highly significant effect on school uniform as reflected in the mean value for the school uniform ( $t=14,67$ $\mathrm{p}<.0005)$. This means that, there is a statistically significant difference in the 
cost of uniform for the students in day schools and in boarding schools. This difference is not by chance, an indication that those parents with children in boarding schools always spend more on uniform compared to the parents with children in day schools.

On the relationship between the cost of school uniform and access to secondary education, the results indicate that there is a strong correlation between the unit cost of education met by the household and enrolment $(\mathrm{r}=$ $0.834, \mathrm{~N}=333, \mathrm{p}<0.001)$. This suggests that, the amount of money that parents spend to buy school uniform correlates with enrolment, implying that, the more the cost of uniform the more the probability of not enrolling children in secondary education.

The findings of this study mimics the work of a Committee constituted to establish the cost of uniform in Melbourne Australia (2007) which established that, parents with girls in secondary schools spends more money on uniform than the parents of the boys. Specifically, on average the cost of girl's uniform was $\$ 586.62$ while for the boys the cost of uniform was $\$ 491.31$, an indication that, the cost of the girl's uniform is $9 \%$ higher than that of the boys. In comparison, in Tharaka South Sub-County, the cost of uniform for the girls is $12 \%$ higher than the cost of uniform for the boys. This is an indication that the cost of education for the girls is higher in Tharaka south Sub-county than in Australia. The gender differences on uniform cost can typically be associated to girls buying more clothing that constitute school uniform than the boys and the aspect of the boys being more likely to buy more generic garments such as shirts and trousers.

\section{Conclusion}

Based on the foregoing discussion, it can be concluded that indeed there are cost differentials on school uniform with respect to students' age, gender, class level and category of the school. On gender, the study established that the cost of uniform for girls is $12 \%$ higher than that of boys. It's also concluded that students in boarding schools spend more money on uniform than those in day school at Ksh 4,779 and Ksh 4,143 respectively. The results also lead to conclusion that school uniform cost varies with class level where parents who have children in form one pay more on school uniform compared to those in other classes. On average, a student in Form 1 spends Ksh 5,375 on uniform compared to parents in Form two who spends Ksh 4,706 Form three, Ksh 3,917 and Form four 4,325. Finally, the study established that there is a correlation between the cost of education and access to secondary education. 


\section{Recommendation}

- The study established that household on average spends Ksh 5,375 on uniform especially in form one. This study, therefore, recommends that government or other educational stakeholders should support buying of school uniform for the children joining secondary education in Form 1 as a way of increasing enrolment.

- The study established that girls spend more money on school uniform than boys. It is therefore recommended that the uniform for girls be subsidized by the government.

- Students in boarding schools spend more on uniform than those in day schools, this calls for the establishment of more day schools in order to encourage more students to enrol in those schools..

\section{References}

1. Anderson, W. (2002). School dress code and uniform policies. Educational Management, 4, 13-15.

2. Basu, K. (1999). Child labor: Cause, consequence, and cure, with remarks on international labour standards. Journal of Economic Literature, 37(3), 1083 1119.http://dx.doi.org/10.1257/jel.37.3.1083

3. Bonke, J. (2013), Do Danish children and young people receive pocket money? The Rockwool Foundation Research Unit, Copenhagen. Study Paper No. 57.

4. Brunsma, D. L. (2005), Uniforms in public schools: A decade of research and debate. Lanham, MD: Rowman \& Littlefield.

5. Duflo, Esther, Pascaline Dupas, Michael Kremer, Samuel Sinei, (2006) "Education and HIV/AIDS Prevention: Evidence from a Randomized Evaluation in Western Kenya," World Bank Policy Research Working Paper 4024, October 2006.

6. Daugherty, R. (2001). School uniforms: Can voluntary programs work? Experimenting in an at-risk school. Paper presented at Education Law Association 47th Annual Conference, Albuquerque, New Mexico, and November 15-17, 2001. ED 461181

7. Draa, V. A. (2005). School uniforms in urban public high schools. (Doctoral Dissertation) Retrieved from ERIC database. (ED497409).

8. The government of Kenya, (2005). Kenya Education Sector Support Programme: Delivering Quality Education and Training to all Kenyans. Nairobi: Government Printer.

9. Kremer, Michael, Sylvie Moulin, and Robert Namunyu, (2002) "Unbalanced Decentralization: Results of a Randomized School Supplies Provision Program in Kenya," Mimeo Brookings Institution, Washington D.C., November 2002. 
10. Lumsden, L., \& Miller, G. (2002). Dress codes and uniforms. Research Roundup, 18(4), 1-5.

11. MoEST, (2003). FPE: Every Child in School. Nairobi: MoEST

12. Ohba, A. (2009). Does Free Secondary Education Enable the Poor to Gain Access? A Study from Rural Kenya, CREATE Pathways to Access, Research Monograph No 21.

13. Orodho. J. A (2009). Elements of Education and Social Science Research Methods. Maseno Kenya: Kanezja Publisher

14. Schultz, T. P. (1993). Investments in the schooling and health of women and men: quantities and returns. Journal of Human Resources, 28 (4), 694-734. http://dx.doi.org/10.2307/146291.

15. Yeung, R. (2009). Are school uniforms a good fit? Results from the ECLS -K and the NELS. Educational Policy, 23(6), 847-874.

\section{Appendix 1 Figures}

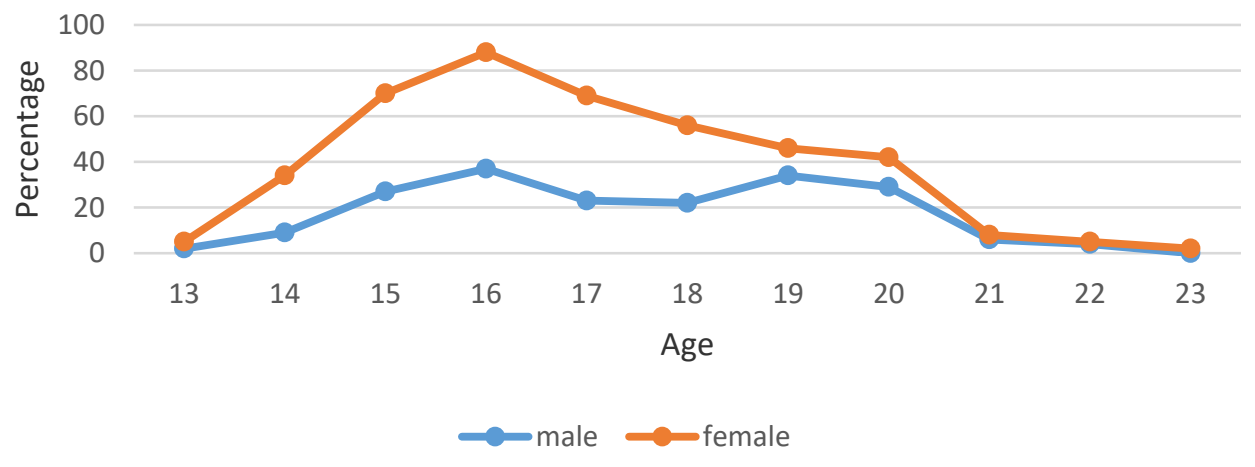

Figure 1 Age Distribution of Students by Gender

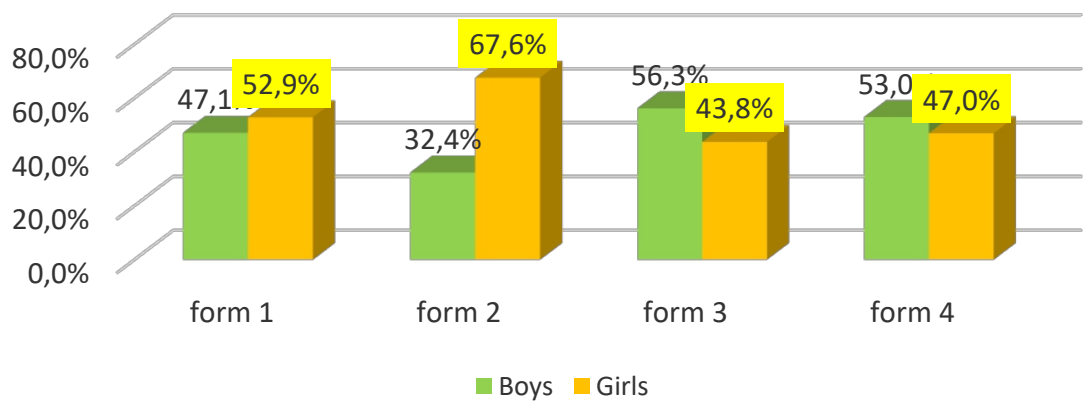

Figure 2 Gender Distributions of Students by Classes 


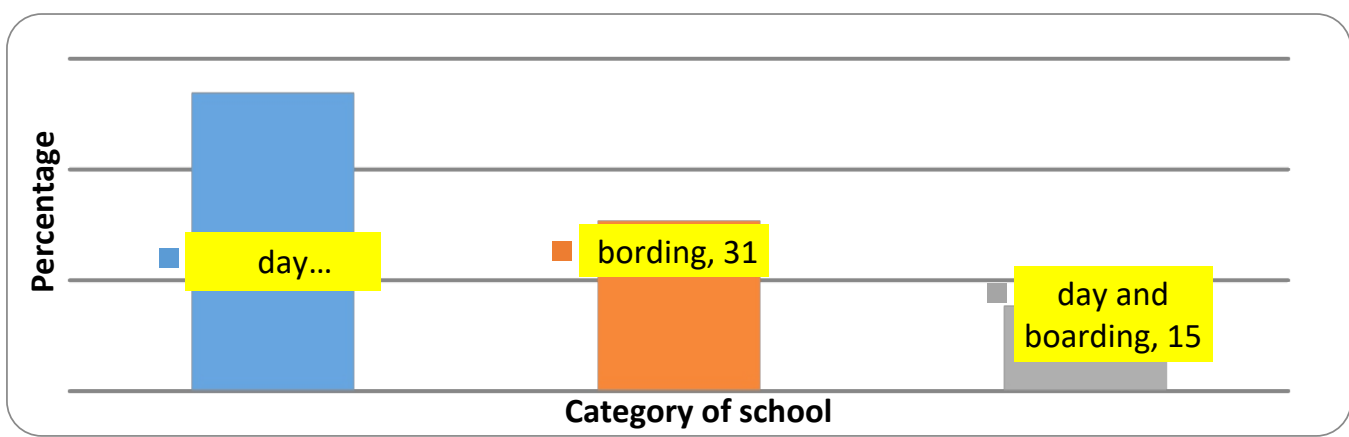

Figure 3 Category of secondary schools in Tharaka South Sub County

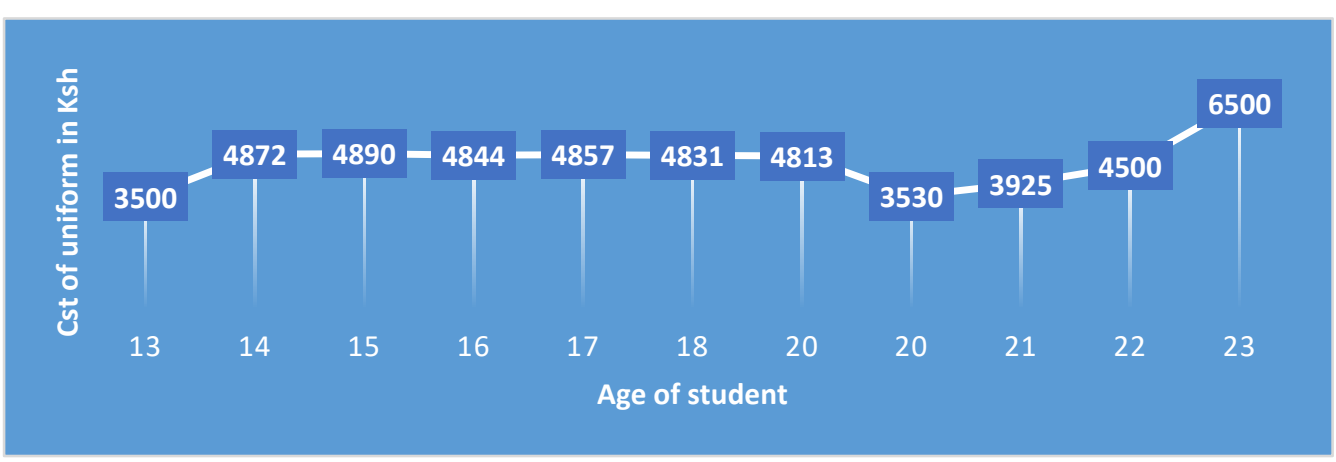

Figure 4 Mean school uniform cost by age of students

Appendix 2. Tables

Table 1 School uniform by gender

\begin{tabular}{llllll}
\hline Gender & Obs & Mean & Std. Dev. & Min & Max \\
\hline Male & 179 & 4035.75 & 3235.461 & 400 & 24000 \\
Female & 222 & 5094.73 & 5541.043 & 950 & 42000 \\
\hline
\end{tabular}

Table 2 Uniform cost by type of school

\begin{tabular}{llllll}
\hline Type of school & Obs & Mean & Std. Dev. & Min & Max \\
\hline Day & 167 & 4143.023 & 3670.183 & 800 & 14000 \\
Boarding & 201 & 4779.966 & 5044.575 & 400 & 22000 \\
\hline
\end{tabular}

Table 3 Cost of school uniform by class

\begin{tabular}{llllll}
\hline Class & Obs & Mean & Std. Dev. & Min & Max \\
\hline Form 1 & 100 & 5375. & 4227.878 & 1000 & 42000 \\
Form 2 & 138 & 4706 & 4443.215 & 950 & 40000 \\
Form 3 & 95 & 3917 & 3747.417 & 500 & 35000 \\
Form 4 & 68 & 4325 & 6527.333 & 400 & 40000 \\
\hline
\end{tabular}


Table 4: The relationship between school uniform cost and student's age and gender

\begin{tabular}{llll}
\hline & & Age of child & $\begin{array}{l}\text { Child's gender } \\
(1=\text { female })\end{array}$ \\
\hline Uniform & Pearson Correlation & $.858^{* *}$ & $.824^{*}$ \\
& Sig. (2-tailed) & 0.000 & 0.000 \\
& $\mathrm{~N}$ & 401 & 401 \\
\hline & $*$ Correlation is significant at the 0.05 level (2-tailed).
\end{tabular}

Table 5: T-test on the cost of school uniform by category of school

Category of school

Variable

$\frac{\text { Day school }}{(\mathrm{n}=150)} \quad \underline{\text { Boarding }} \quad \underline{t \text {-value }} \quad \underline{\text { sig }}$

School uniform $\quad$ M

4143.02

(3670)

14.67

0.000

SD

5196.76

(7281) 